\title{
Spatial and Seasonal Distribution Study and Correlation Analysis of Aerosol and PM2.5 in Beijing City Based on MODIS Data
}

\author{
Ye wei, Song wei \\ Laboratory of Environmental Protection Technology on Water Transport, Tianjin Research Institute for Water \\ \&Transport Engineering, Ministry of Transport, Tianjin, China
}

\begin{abstract}
The inversion of aerosol optical depth (AOD) of Beijing in each four seasons of 2014 year was carried out in this paper. The results show that, in seasonal distribution, the AOD of Beijing city was lower in winter and spring, stable in summer and autumn. In spatial distribution, the AOD is large in the centre area and the southwest area of Beijing city and small in the suburbs of Beijing city, because there's less air pollution. Further exploration of correlation between AOD and PM2.5, $\mathrm{R}^{2}$, the squared value of the correlation coefficient of them (R) is 0.03 in spring, 0.74 in summer, 0.45 in fall, 0.44 in winter. It can be seen that the correlation of PM2.5 and AOD was higher in summer, lower in spring, and the correlation in fall was similar with it in winter.
\end{abstract}

\section{Introduction}

Atmospheric aerosols are defined as suspended particles in the atmosphere in liquid or solid phase. Their dynamic diameter is about 0.001 um - 100 um. The particulates with dynamic diameter less than 10um $\left(\mathrm{PM}_{10}\right)$ and the particulates with dynamic diameter less than 2.5um (PM2.5, able to go directly to the alveoli) have great harm to human health. The increasing of aerosol particles in recent years is supposed to be one of the important reasons of the haze weather of the city and suburbs.

Beijing, as the capital of China, its air quality is obviously affected by human factors, such as urban traffic pollution, municipal construction, industrial gas emissions from surrounding areas and destruction of natural ecological environment. The air is seriously polluted. In order to reduce the influence of pollution sources, the monitoring of urban atmospheric environment quality is particularly important. Aerosol particles has widely been paid attention and studied because of its important role in atmospheric monitoring ${ }^{[1]}$.

Optical Depth is one of the most important parameters of aerosol. As an important physical quantity of atmospheric turbidity, it is a key factor to determine the climate effect of aerosol. At present, there are two methods to obtain the aerosol optical depth (AOD). One is foundation exploration, and the other is satellite remote sensing ${ }^{[2]}$. Foundation exploration can more accurately measure the information of aerosol, but it requires to deploy a large number of ground stations. Besides, this method gets just the data on the spatial point. It is unable to correctly reflect the space-time distribution over large area. On the contrary, the satellite remote sensing method has the characteristics of fast, non-contact, wide coverage. Relative to the foundation exploration method, the satellite remote sensing method can more efficiently get the information of atmospheric aerosol ${ }^{[3]}$.

At present, the aerosol optical depth (AOD) is mainly inversion by the high resolution satellite remote sensing data of the moderate resolution imaging spectroradiometer (MODIS) sensor of Terra/Aqua satellite. MODIS image has 36 channels of data from visible light, near infrared and far infrared band, and has the ability of monitoring of the clouds and aerosols in the aspect of atmospheric monitoring ${ }^{[4-6]}$. Its channel 1 ( $0.620 \sim 0.670 \mu \mathrm{m}$, the red channel) and channel 3 (0.459 $\sim 0.479 \mu \mathrm{m}$, the blue channel) are mainly used for remote sensing observation of aerosol, because their narrow bandwidth is good for the correction of the influence of atmospheric gas absorption uncertainty on the remote sensing of aerosol. The forest is distinguished as dark target by NDVI or the reflectivity of near infared channel $(2.1 \mu \mathrm{m})$, making the advantage of the characteristics of low reflectivity of most of the land surface. Then the surface reflectivity of the research area in red channel and blue channel can be calculated by relevant formula. The dense dark vegetation (DDV) method to determine the surface reflectivity has become the most widely used algorithm in the applications of aresols remote sensing ${ }^{[7-}$ 9].

Since the U.S. government announced the distribution map of PM2.5, the concertration of PM2.5 in Beijing and other cities is especially paid attention to. At present, the PM2.5 monitoring method of the cities, including Beijing, is foundation exploration method, depending on those detection equipments set at fixed sites. As in AOD, the method can not correctly reflect the space-time distribution of PM2.5. Therefore, it is necessary to study on the correlation between PM2.5 and aerosols.

The inversion of AOD from four season in Beijing was carried out based on the MODIS data of 2014 year in the article. Beijing's spatial distribution and seasonal characteristics of aerosol were given through comparative analysis. The correlation between AOD and PM2.5 was analyzed with 2014 full-year measeured data from monitoring sites in Beijing in the article. The correlation coeffients of AOD and PM2.5 in different seasons were given. These results laid the foundation for the subsequent research about the PM2.5 monitoring with remote sensing.

\section{Study area}

Beijing, the capital of the People's Republic of China, The center is located in north latitude 39 $54^{\prime} 20^{\prime \prime}$, longitude $116^{\circ} 25^{\prime} 29^{\prime \prime}$, and the geographical scope is in 
$115.7^{\circ} \sim 117.4^{\circ}$ east longitude, latitude $39.4^{\circ} \sim 41.6^{\circ}$, with a total area of 16410.54 square kilometers.

There is odd arteries of the Taihang Mountains in the west and JunDou Mountain of the Yanshan Mountains in the north. The both mountains intersect in nankouguan ditch, forming a curved, southeast of semicircle mountain known as "Beijing corner", it is around a small plain is the Beijing plain. The average elevation of Beijing is 43.5 meters. The elevation is about $20 \sim 60$ meters in plain region, and generally $1000 \sim 1500$ meters in mountainous region. The geography graph of Beijing city is shown in Figure1.

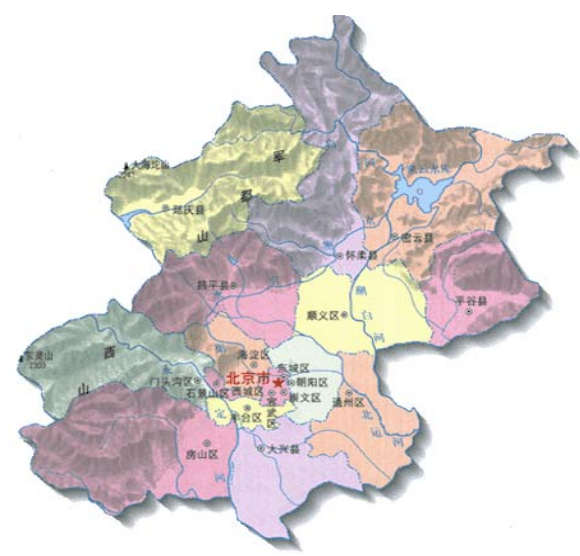

Figure 1. The geography graph of Beijing city

\section{The inversion of aerosol optical depth (AOD)}

\subsection{The basic principle}

The remote sensing analys is about the Characteristics of aerosols is based on the theory of the relationship between the radiant intensity of the atmosphere and the surface reflectance properties. Assume that the surface observed by the satellite is uniform lambert surface, without considering gas absorption the top-of-atmosphere (TOA) reflectance observed by satellite can be expressed as:

$\rho^{*}\left(\mu, \emptyset, \mu_{0}, \emptyset_{0}\right)=\rho_{a}\left(\mu, \emptyset, \mu_{0}, \emptyset_{0}\right)+\frac{T\left(\mu_{0}\right) T(\mu) \rho}{1-\rho s}$

where: $\rho^{*}$ is surface reflectance from satellite observations, $\rho_{\mathrm{a}}$ is atmospheric reflectivity for the whole, $\mu_{0}, \mu, \emptyset_{0}, \emptyset$ are solar zenith angle,satellite zenith angle (observation), solar azimuth,and satellite azimuth,

$\mathrm{T}\left(\mu_{0}\right), \mathrm{T}(\mu)$ are the total atmospheric transmittances, containing both direct and diffuse transmissions for sun illumination and satellite viewing geometry, $\mathrm{s}$ is spherical surface albedo of atmosphere, $\rho$ is the surface reflectance. In fact, $\rho^{*}$ is also a function of aerosol optical thickness. For uniform lambert surface, changing evenly in the vertical direction of atmosphere, TOA can be expressed as $^{[9]}$ :

$\rho^{*}=\frac{\pi \mathrm{L}\left(\tau_{\mathrm{o}}, \mu_{\mathrm{v}}, \emptyset_{\mathrm{v}} ; \mu_{\mathrm{s}}, \emptyset_{\mathrm{s}}\right)}{\mu_{\mathrm{s}} \mathrm{E}_{\mathrm{s}}}$

Where: $\mathrm{L}$ is sensor measurement radiance, $\mathrm{E}_{\mathrm{s}}$ is solar radiant flux of the sensor receivers, $\tau_{0}$ is atmospheric optical depth of the whole layer, $\left(\mu_{s}, \emptyset_{s}\right)$ is the direction of the incident light of the sun, $\left(\mu_{v}, \emptyset_{v}\right)$ is sensor concept, $\mu_{v}, \emptyset_{v} ; \mu_{s}, \emptyset_{s}$ are the observation direction and the direction of the incident solar zenith angle and azimuth angle cosine.

Combining (1) and (2), if the surface reflectance is known, and according to the characteristics of different regions, the types of atmospheric aerosols are determined, the aerosol optical depth can be obtained by the formula; On the other hand, if the aerosol optical depth and the corresponding atmospheric parameters are known, the surface reflectance can be retrieved by the formula.

\subsection{The inversion model}

At present, the most commonly used aerosol inversion method is DDV algrithm. DDV is mainly based on vegetation index or near infrared band reflectance performance to distinguish, so this method is suitable for the dense vegetation area, and Holben is used to distinguish DDV from the mid infrared band (3.8 $\mu$ $\mathrm{m})$.And Kaufman et al. Considering the diversity of the surface coverage, the relationship between the three different regions of the band and the relationship between the surface, these three bands are blue band $(0.47 \mu \mathrm{m})$, red band $(0.66 \mu \mathrm{m})$ and mid infrared band $(2.1 \mu \mathrm{m})$. According to the experimental results of Kaufman ${ }^{[10]}$, the relationship between the surface reflectance of the red blue channel and the surface reflectance of $2.1 \mu \mathrm{m}$ can be expressed as:

$\rho_{\mathrm{R}}=\rho_{2.1}^{*} / 2$
$\rho_{\mathrm{B}}=\rho_{2.1}^{*} / 4$

Where: $\rho_{B}$ is the surface reflectance under blue channel $(0.47 \mathrm{~mm}), \rho_{R}$ is the surface reflectance under red channel $(0.0 .66 \mu \mathrm{m})$.

In 2007, Levy et al. To improve the relationship between the DDV and the influence of the vegetation index and the scattering angle on the surface reflectance, the new ratio relation is given.

$\rho_{\mathrm{R}}=\rho_{2.1} \times(\varepsilon+0.002 \delta-0.27)+0.00025 \delta+0.033$

(5)

$\rho_{\mathrm{B}}=\rho_{R} \times 0.49+0.005$

Where $\varepsilon$ is can be obtained by MODIS's $1.24 \mu \mathrm{m}$ and 2.1 $\mu \mathrm{m}$ channel, $\delta$ is scattering angle, can be expressed as the solar zenith angle, satellite zenith angle and relative azimuth angle function, the method can be expressed as: $\delta=\arccos \left(-\cos \mu_{0} \cos \mu+\sin \mu_{0} \sin \mu \cos \emptyset\right)$

\subsection{Data and method for inversion}

Remote sensing data: MODIS L1B 1KM data in January 30, 15th April, 16th July and 20th October of 2014 year.

Method: Referring to the method of Fan Jiao, Guo Baofeng, He Hongchang, et al ${ }^{[12]}$. Firstly determining the type of aerosol, then establishing the LUT, and then use the IDL programming in ENVI5.0 to inversion according to the following process: 


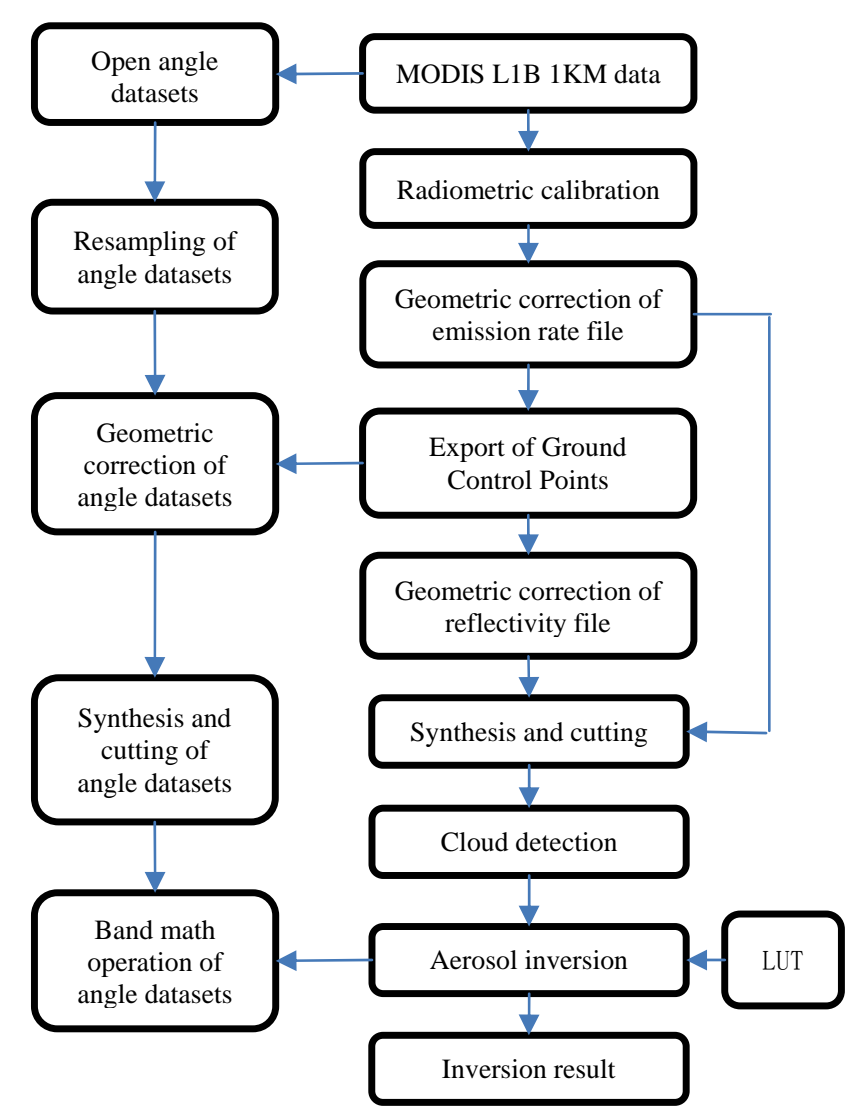

Figure 2. Schematic diagram for aerosol retrieval in the study.

\subsection{The results of inversion}

The results of aerosol inversion of four seasons in Beijing are shown in Figure 3.

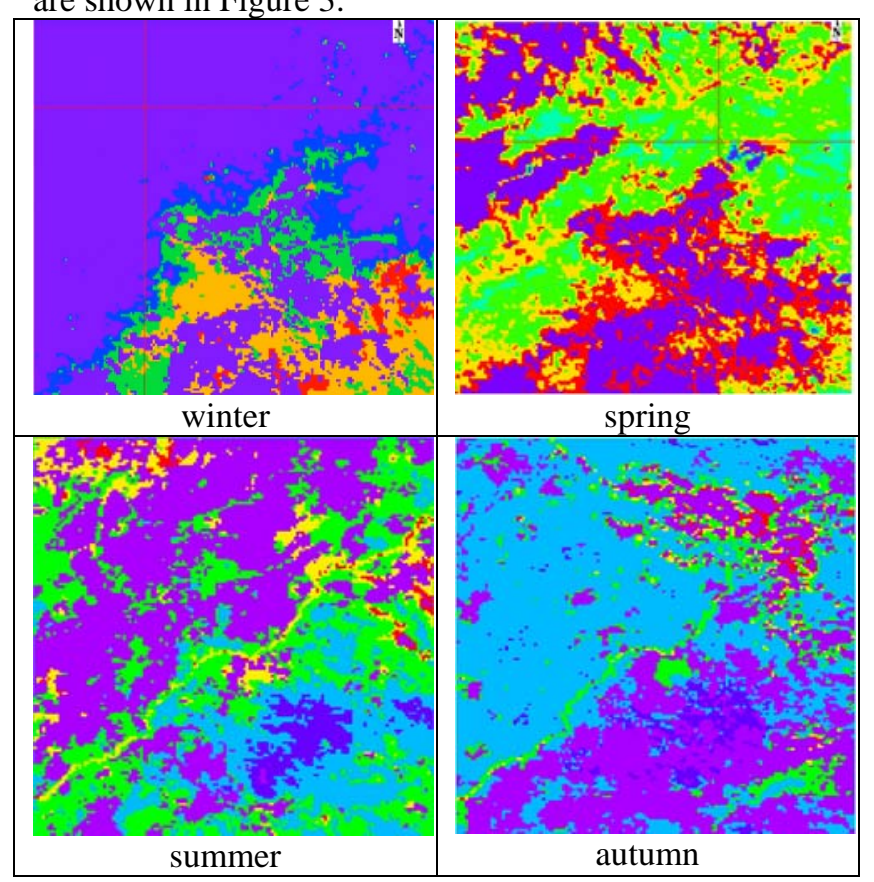

Figure 3. The aerosol distribution map of four seasons of 2014 year in Beijing

The results of aerosol retrieval in four seasons in Beijing city can be seen that from the time-series analysis, the pollution of air in winter and spring is more serious than that in summer and autumn, and the concentration of aerosol is relatively large and the air quality is poor.

From the spatial analysis, the central area of Beijing and the southwest region are densely populated, the traffic developed area, and the aerosol optical depth (AOD) is larger, while the other suburban area is relatively small.

\section{The analysis of pm2.5 data of Beijing}

\subsection{The source of PM2.5 of Beijing}

According to relevant research, the regional transport contribution of PM2.5 in Beijing city in recent years accounted for about $28-36 \%$, the contribution of local pollution emissions accounted for $64-72 \%$. In the local pollution, motor vehicles, coal, industrial production, dust as the main source, respectively, $31.1 \%, 22.4 \%, 18.1 \%$ and $14.3 \%$, catering, car repair, livestock breeding, construction and other emissions of about PM2.5 14.1\%, as shown in Figure 4and Figure 5.
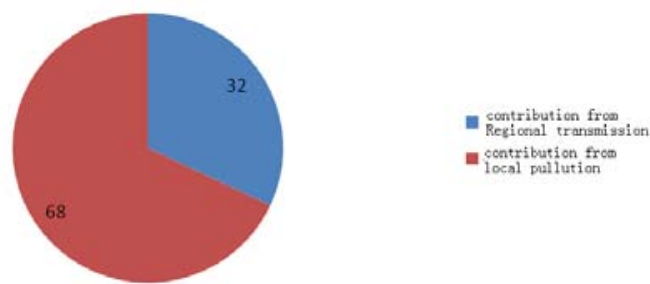

Figure 4. The source contribution chart of PM2.5 of Beijing

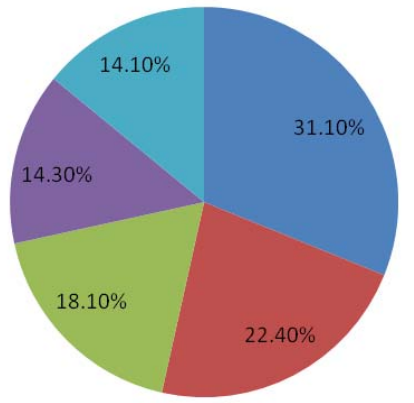

- Vehicle

ncoal-fired

industrial

ablowing dust

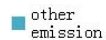

Figure 5. The source classification chart of PM2.5 of Beijing

\subsection{Data processing of PM2.5 from environmental monitoring sites in Beijing}

\subsubsection{Data source}

Beijing PM2.5 data from the Beijing City Environmental Protection Testing Center website, data for the full 2014 year, the data include PM2.5, PM10, and AQI data. Beijing city existing 35 ambient air test site (site distribution, see Figure 6), part of the site is every 1 hours to detect a data. 


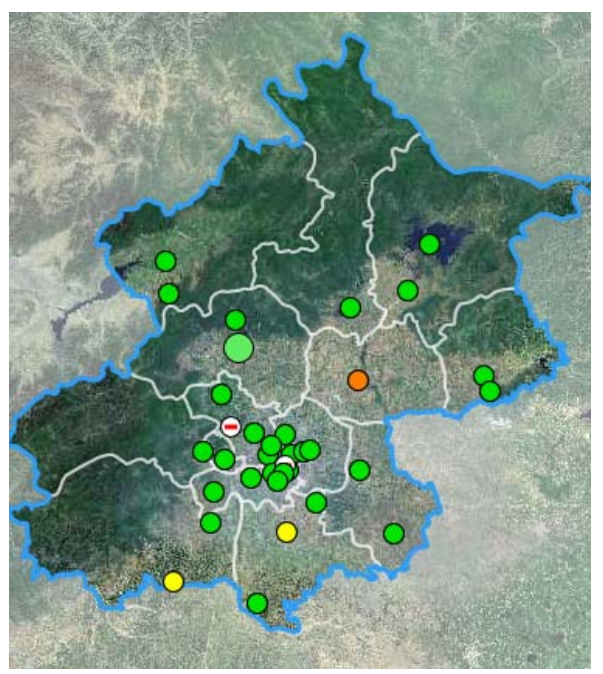

Figure 6. The location map of environment air monitoring sites in Beijing

\subsubsection{Data Processing}

According to January, November, December for the winter, February, March, April for the spring, May, June, July for the summer, August September, October for the fall, the data will be divided into four seasons in 201412 months. The average PM2.5 concentration of each month was calculated by the daily data, and then the average concentration of PM2.5 in each season was calculated according to the seasonal average. The final calculation of the various sites of the PM2.5 average concentration of the four seasons is shown in Table 1.

Table 1 Average concentrations of PM2.5 in each season Unit: microgram per cubic meter

\begin{tabular}{|c|c|c|c|c|}
\hline season & Sping & Summer & autumn & winter \\
\hline Dongsi & 210.1845 & 49.4389 & 42.7181 & 83.5653 \\
\hline $\begin{array}{c}\text { Temple of } \\
\text { Heaven }\end{array}$ & 190.3472 & 50.3798 & 41.6431 & 88.8271 \\
\hline Guanyuan & 189.7659 & 50.5986 & 34.0833 & 82.9667 \\
\hline $\begin{array}{c}\text { Wan } \\
\text { Nishinomiya }\end{array}$ & 210.8651 & 49.7111 & 43.1347 & 102.7346 \\
\hline $\begin{array}{c}\text { Olympic } \\
\text { Sports Center }\end{array}$ & 198.2044 & 56.2153 & 44.9931 & 91.0208 \\
\hline $\begin{array}{c}\text { Agricultural } \\
\text { Exhibition }\end{array}$ & 208.3472 & 52.0528 & 48.1275 & 111.4797 \\
\hline Hall & & & & \\
\hline Wanliu & 207.6746 & 52.9764 & 39.5708 & 94.4944 \\
\hline $\begin{array}{c}\text { Northern New } \\
\text { Area }\end{array}$ & 201.8948 & 49.7250 & 30.6181 & 113.1659 \\
\hline $\begin{array}{c}\text { Botanical } \\
\text { Garden }\end{array}$ & 182.4147 & 46.8986 & 25.5874 & 76.7840 \\
\hline $\begin{array}{c}\text { Fengtai } \\
\text { garden }\end{array}$ & 234.6806 & 51.8269 & 47.1125 & 121.8931 \\
\hline Yungang & 188.4524 & 52.6097 & 35.2903 & 110.3014 \\
\hline Gucheng & 150.9583 & 56.5125 & 39.7958 & 91.9861 \\
\hline Fangshan & 200.3016 & 57.0653 & 43.0014 & 136.2085 \\
\hline Daxing & 217.2321 & 59.4083 & 59.3208 & 142.6750 \\
\hline Yizhuang & 204.6488 & 65.0020 & 58.9847 & 145.2458 \\
\hline Tongzhou & 224.8155 & 72.0443 & 59.8319 & 170.7847 \\
\hline Shunyi & 200.4067 & 53.3750 & 40.3833 & 85.6958 \\
\hline Changping & 177.8294 & 38.1528 & 25.9653 & 89.8146 \\
\hline Men Tougou & 191.9484 & 45.7958 & 24.8889 & 76.6461 \\
\hline Pinggu & 191.5303 & 42.3694 & 38.8292 & 82.5042 \\
\hline Huairou & 179.3175 & 35.8897 & 25.3606 & 55.7753 \\
\hline Miyun & 182.8849 & 32.2722 & 31.5911 & 64.4417 \\
\hline Yanqing & 180.8492 & 36.9444 & 25.8569 & 80.5694 \\
\hline Dingling & 201.3472 & 33.5042 & 21.8069 & 67.5989 \\
\hline Ba Daling & 149.5218 & 43.5722 & 23.8417 & 40.8486 \\
\hline
\end{tabular}

\begin{tabular}{|c|c|c|c|c|}
\hline $\begin{array}{c}\text { Miyun } \\
\text { Reservoir }\end{array}$ & 152.1329 & 28.6417 & 42.4876 & 32.7285 \\
\hline Dong Gaocun & 165.2679 & 47.8528 & 42.9306 & 86.1798 \\
\hline Yong Ledian & 220.3472 & 75.3240 & 53.7583 & 198.7722 \\
\hline Yufa & 197.4588 & 62.5889 & 52.0653 & 161.2983 \\
\hline Liuli river & 212.0833 & 63.1458 & 54.4806 & 206.5340 \\
\hline Qianmen & 209.1071 & 73.0051 & 55.6444 & 107.6569 \\
\hline $\begin{array}{c}\text { Yongding } \\
\text { door }\end{array}$ & 200.6667 & 55.6222 & 59.8597 & 108.4572 \\
\hline $\begin{array}{c}\text { Xizhimen } \\
\text { North }\end{array}$ & 190.5635 & 54.8972 & 68.5167 & 94.1025 \\
\hline Nan Sanhuan & 222.0972 & 59.7597 & 56.8028 & 115.7528 \\
\hline Dong Sihuan & 201.2063 & 57.8236 & 69.8470 & 118.8264 \\
\hline
\end{tabular}

\subsubsection{Data analysis}

According to the data from table 1, we can draw a histogram to display intuitive changes every season PM2.5, as Figure 7 and Figure 8 shows.

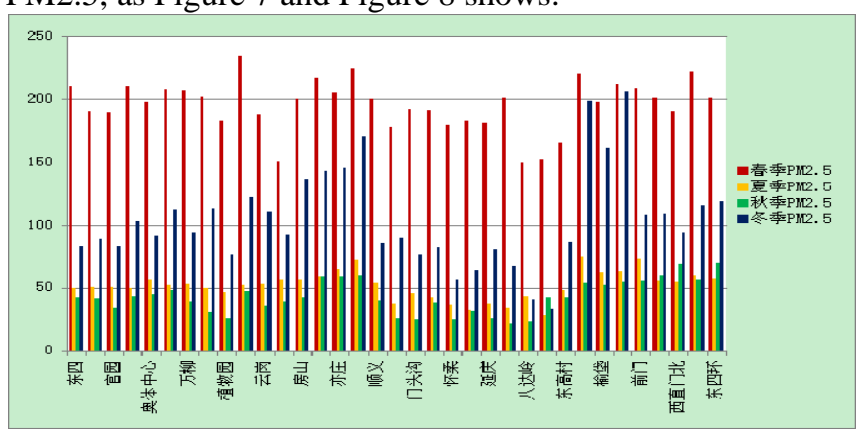

Figure 7 Average concentrations of PM2.5 on each site in each season

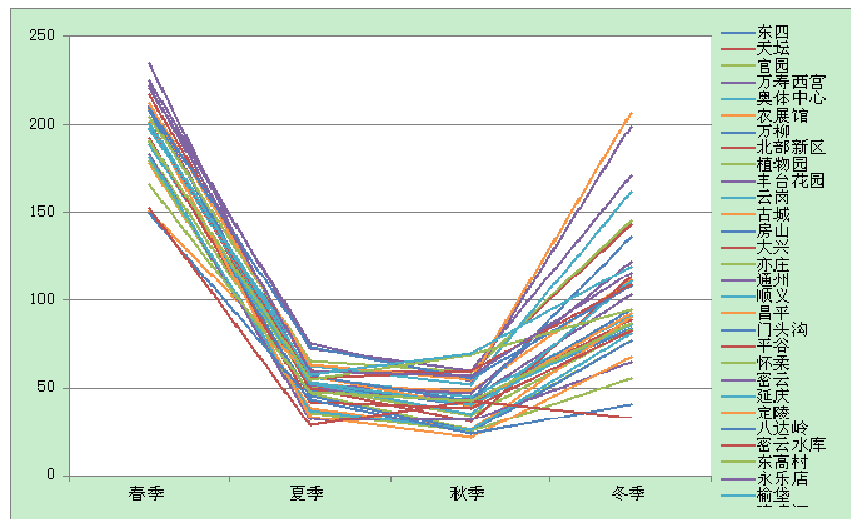

Figure 8 Seasonal PM2.5 concentrations change on each site

By the two pictures above, we can see that Beijing overall PM2.5 feature in the time series show obvious seasonal characteristics, namely in the winter and spring of PM2.5 higher, in the summer and autumn of PM2.5 relatively low. Showing a growth and decline trend.

\section{The AOD and the relativity analysis of pm2.5 of Beijing}

\subsection{AOD and PM2.5 data preprocessing}

Based on chapter 3 as a result, the performance of aerosol due to the data of aerosol optical thickness value is limited, we will be the thickness of the aerosol value according to seasonal is divided into the corresponding data and the matching correlation analysis. Similarly, PM2.5 measurement sites is not completely in the work 
state, some sites for various reasons in one day to work of data collection, so we in the data on the control of the also can't get a complete site control data table, draw a part of the site after data validity screening of PM2.5 and AOD data reference table are shown in table 2.

Table 2. The comparison table of PM2.5 and AOD data in each season.

\begin{tabular}{|c|c|c|c|c|c|c|c|c|}
\hline \multirow{2}{*}{$\begin{array}{c}\text { season } \\
\text { site } \\
\text { Data } \\
\text { type }\end{array}$} & \multicolumn{2}{|c|}{ Spring } & \multicolumn{2}{|c|}{ Summer } & \multicolumn{2}{|c|}{ autumn } & \multicolumn{2}{|c|}{ winter } \\
\hline & PM & AO & PM2 & AO & $\begin{array}{c}\text { PM2 } \\
5\end{array}$ & $\mathrm{AO}$ & PM2. & $\mathrm{AO}$ \\
\hline \multirow[t]{2}{*}{ Dongsi } & 210. & 0.67 & $\frac{.5}{49.4}$ & 1.32 & 42.7 & 1.51 & 83.56 & 0.94 \\
\hline & $\begin{array}{c}184 \\
5\end{array}$ & 16 & 389 & 32 & 181 & 93 & 53 & 98 \\
\hline \multirow{2}{*}{$\begin{array}{l}\text { Temple } \\
\text { of } \\
\text { Heaven }\end{array}$} & 190. & 0.02 & 50.3 & 1.15 & 41.6 & 1.67 & 88.82 & 0.13 \\
\hline & $\begin{array}{c}347 \\
2\end{array}$ & 46 & 798 & 58 & 431 & 11 & 71 & 39 \\
\hline \multirow{2}{*}{$\begin{array}{l}\text { Olympi } \\
\text { c Sports } \\
\text { Center }\end{array}$} & 198. & 0.07 & 56.2 & 1.41 & 44.9 & 1.11 & 91.02 & 0.72 \\
\hline & $\begin{array}{c}204 \\
4\end{array}$ & 77 & 153 & 72 & 931 & 44 & 08 & 30 \\
\hline \multirow{3}{*}{$\begin{array}{l}\text { Agricul } \\
\text { tural } \\
\text { Exhibiti } \\
\text { on Hall } \\
\end{array}$} & 208. & 0.04 & 52.0 & 1.48 & 48.1 & 1.55 & 111.4 & 0.19 \\
\hline & 347 & 27 & 528 & 80 & 275 & 57 & 797 & 52 \\
\hline & 2 & & & & & & & \\
\hline \multirow{3}{*}{$\begin{array}{l}\text { Botanic } \\
\text { al } \\
\text { Garden }\end{array}$} & 182. & 0.16 & 46.8 & 1.77 & 25.5 & 1.95 & 76.78 & 1.05 \\
\hline & 414 & 58 & 986 & 53 & 874 & 68 & 40 & 67 \\
\hline & 7 & & & & & & & \\
\hline \multirow{2}{*}{$\begin{array}{l}\text { Fengtai } \\
\text { garden }\end{array}$} & 234. & 0.02 & 51.8 & 1.48 & 47.1 & 1.73 & 121.8 & 0.42 \\
\hline & $\begin{array}{c}680 \\
6\end{array}$ & 36 & 269 & 98 & 125 & 72 & 931 & 87 \\
\hline \multirow{2}{*}{$\begin{array}{c}\text { Fangsh } \\
\text { an }\end{array}$} & 200. & 0.47 & 57.0 & 1.39 & 43.0 & 1.46 & 136.2 & 0.98 \\
\hline & $\begin{array}{c}301 \\
6\end{array}$ & 45 & 653 & 66 & 014 & 89 & 085 & 81 \\
\hline \multirow[t]{2}{*}{ Daxing } & 217. & 0.14 & 59.4 & 1.54 & 59.3 & 1.56 & 142.6 & 0.87 \\
\hline & $\begin{array}{c}232 \\
1\end{array}$ & 61 & 083 & 90 & 208 & 45 & 750 & 30 \\
\hline \multirow[t]{2}{*}{ Shunyi } & 200. & 0.18 & 53.3 & 1.42 & 40.3 & 1.69 & 85.69 & 0.06 \\
\hline & $\begin{array}{c}406 \\
7\end{array}$ & 46 & 750 & 71 & 833 & 35 & 58 & 47 \\
\hline \multirow{2}{*}{$\begin{array}{c}\text { Changp } \\
\text { ing }\end{array}$} & 177. & 0.24 & 38.1 & 1.73 & 25.9 & 1.96 & 89.81 & 0.13 \\
\hline & 829 & 74 & 528 & 32 & 653 & 01 & 46 & 76 \\
\hline \multirow{3}{*}{ Huairou } & 179 & 0.22 & 35.8 & 1.77 & 25.3 & 1.96 & 55.77 & 1.41 \\
\hline & 317 & 09 & 897 & 35 & 606 & 84 & 53 & 96 \\
\hline & 5 & & & & & & & \\
\hline \multirow[t]{2}{*}{ Miyun } & 182. & 0.15 & 32.2 & 1.88 & 31.5 & 1.85 & 64.44 & 1.26 \\
\hline & $\begin{array}{c}884 \\
9\end{array}$ & 74 & 722 & 32 & 911 & 00 & 17 & 53 \\
\hline \multirow{2}{*}{$\begin{array}{c}\mathrm{Ba} \\
\text { Daling }\end{array}$} & 149. & 0.11 & 43.5 & 1.63 & 23.8 & 1.98 & 40.84 & 1.62 \\
\hline & $\begin{array}{c}521 \\
8\end{array}$ & 69 & 722 & 67 & 417 & 79 & 86 & 00 \\
\hline \multirow{2}{*}{$\begin{array}{l}\text { Miyun } \\
\text { Reservo } \\
\text { ir } \\
\end{array}$} & 152. & 0.04 & 28.6 & 1.90 & 42.4 & 1.65 & 32.72 & 1.82 \\
\hline & $\begin{array}{c}132 \\
9\end{array}$ & 70 & 417 & 24 & 876 & 60 & 85 & 97 \\
\hline \multirow[t]{2}{*}{ Yufa } & 197. & 0.09 & 62.5 & 1.28 & 52.0 & 1.48 & 161.2 & 0.15 \\
\hline & $\begin{array}{c}458 \\
8\end{array}$ & 80 & 889 & 29 & 653 & 56 & 983 & 86 \\
\hline \multirow{2}{*}{$\begin{array}{l}\text { Liuli } \\
\text { river }\end{array}$} & 212. & 0.03 & 63.1 & 1.28 & 54.4 & 1.42 & 206.5 & 0.03 \\
\hline & 083 & 78 & 458 & 88 & 806 & 60 & 340 & 65 \\
\hline \multirow{2}{*}{$\begin{array}{c}\text { Qianme } \\
n\end{array}$} & 209. & 0.07 & 73.0 & 1.12 & 55.6 & 1.42 & 107.6 & 0.49 \\
\hline & $\begin{array}{c}107 \\
1\end{array}$ & 43 & 051 & 92 & 444 & 88 & 569 & 62 \\
\hline \multirow{3}{*}{$\begin{array}{c}\text { Nan } \\
\text { Sanhua } \\
\text { n }\end{array}$} & 222. & 0.14 & 59.7 & 1.34 & 56.8 & 1.41 & 115.7 & 0.52 \\
\hline & 097 & 60 & 597 & 86 & 028 & 27 & 528 & 15 \\
\hline & 2 & & & & & & & \\
\hline Dong & 201. & 0.13 & 57.8 & 1.38 & 69.8 & 1.69 & 118.8 & 0.24 \\
\hline Sihuan & 206 & 52 & 236 & 31 & 470 & 12 & 264 & 48 \\
\hline
\end{tabular}

\subsection{AOD and PM2.5 correlation analysis}

Section. Based on the screening effectiveness of PM2.5 in Beijing site with AOD data table (table 2), respectively, the four seasons of AOD and PM2.5 data correlation analysis, get the square of the four seasons correlation coefficient $\mathrm{R}$ of the two values, the results are shown in figure $9,10,11,12$.

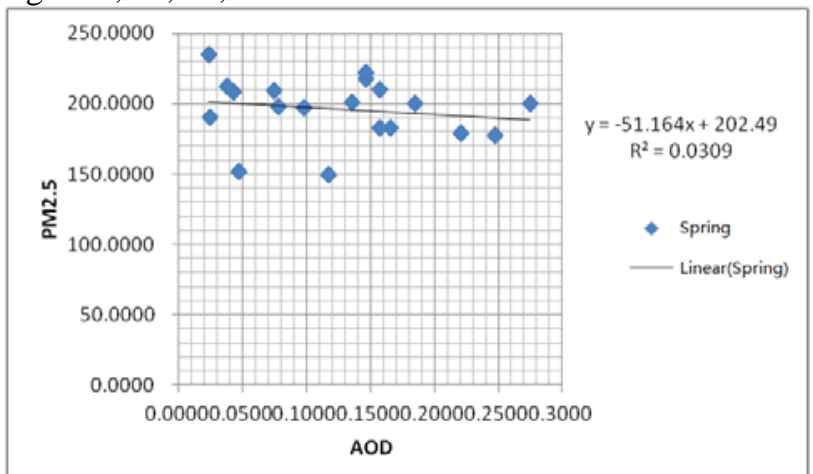

Figure 9 The correlation analysis figure of PM2.5 and AOD of Beijing in Spring

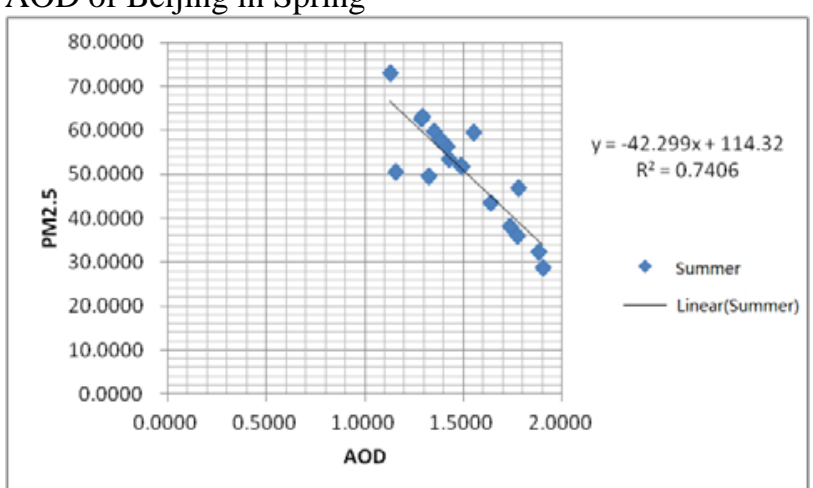

Figure 10 The correlation analysis figure of PM2.5 and AOD of Beijing in summer

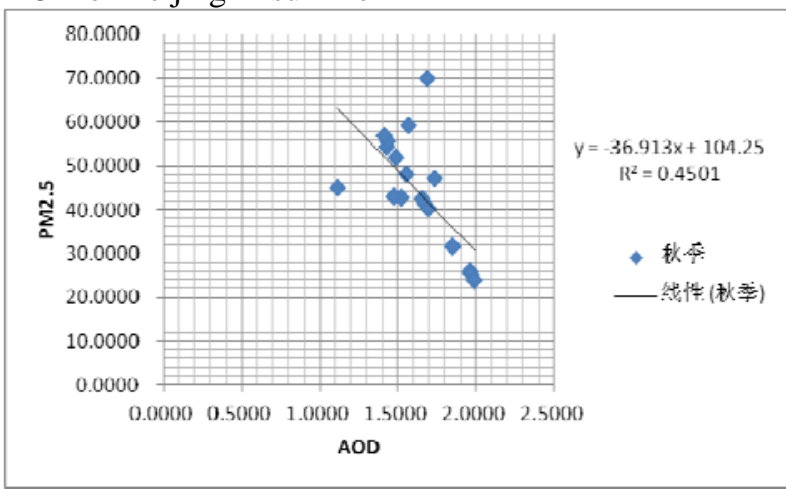

Figure 11. The correlation analysis figure of PM2.5 and AOD of Beijing in autumn

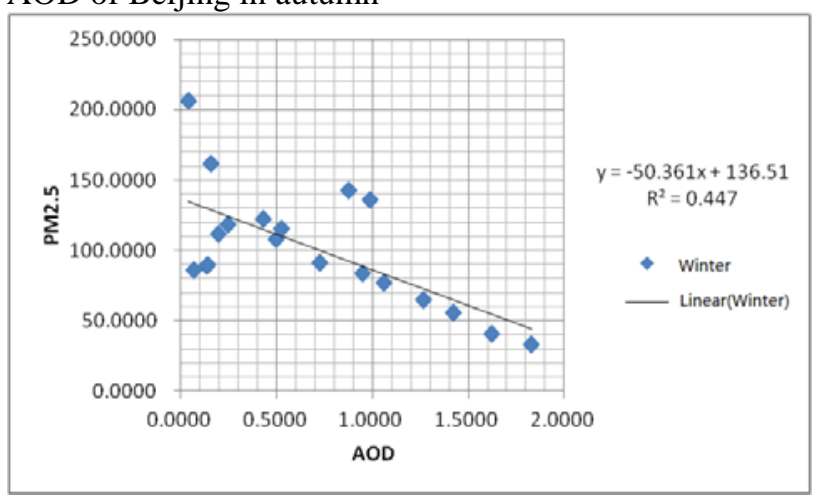

Figure 12. The correlation analysis figure of PM2.5 and AOD of Beijing in winter

Can be seen by the above figure, most images present a negative correlation is the case, it shows that a large area 
in PM2.5 concentrations of AOD value relatively small, the theoretical basis of the above mentioned AOD is consistent, namely in the area of PM2.5 is larger, the air pollution is larger, the transparency of air is relatively low, AOD data is small, light is not entirely through go to, and in PM2.5 smaller area, the air pollution is low, so the corresponding AOD is larger, the stronger the light through the air capacity.

\section{Conclusion and prospect}

In this paper, the aerosol optical depth of the four seasons in Beijing area is retrieved by MODIS data, and the spatial distribution and seasonal variation of the aerosol optical depth (AOD) in Beijing are analyzed, the spatial distribution and seasonal variation of PM2.5 in Beijing city were analyzed by the data of PM2.5 monitoring station in Beijing, and the correlation analysis between AOD and PM2.5 was carried out. The following conclusions are drawn from this study:

(1) Through the aerosol inversion results, it can be concluded that there are some differences in the space, in the suburbs of Beijing, the air is better, and the AOD is smaller. While in urban areas, the air transparency is poor, and the corresponding AOD is relatively large. In the timing, the Beijing winter and spring in the AOD than in the summer and autumn, it is the air transparency is poor.

(2) Through the analysis of the PM2.5 data, the change characteristics of PM2.5 in the time series of Beijing city were highest in the spring, after a continuous decline in the summer and fall to the bottom of the trough, to the beginning of the winter to rise to the peak.

(3) By the correlation analysis between AOD and PM2.5, the AOD and PM2.5 data are consistent with the spatial distribution, and the high value areas are located in the downtown area of Beijing and southwest of the region, other regions are relatively low value.

(4) Correlation analysis results also show that PM2.5 and AOD are negative correlation, PM2.5 concentration is larger, and the corresponding AOD data is small, and vice versa. The square value of PM2.5 and AOD correlation coefficient $\mathrm{R}$ was 0.03 in spring, 0.74 in summer, 0.45 in autumn and 0.44 in winter. The correlation between the two in the summer, the worst in the spring, autumn and winter, the basic agreement. While the correlation between the two is also obvious seasonal variation trend, the spring of $\mathrm{R} \wedge 2$ to a significant increase in the summer, while the autumn and winter were significantly reduced, the basic stability of the two seasons. Analysis of its causes, mainly in the spring windy weather, air transport in the city of rapid change in the city, the time of the day AOD is relatively poor, resulting in urban and suburban PM2.5 and AOD relative to other seasons is poor.

Through this study, it is found that the MODIS data retrieval aerosol optical depth can be set up by the PM2.5 observation and prediction system, but some problems need to be further improved:

(1) DDV algorithm, also called dense vegetation, with better operability, the inversion effect is relatively good, but in the time range of September to March, so the air quality of Beijing city in winter and spring, the method of inversion results is poor; In the area, there are some limitations in the area of the area of vegetation cover, the inversion effect is also poor.

(2) The correlation analysis results between PM2.5 and AOD show that the linear relationship between the two is different in different seasons, that is to say that the linear coefficients of the corresponding linear coefficients will fluctuate within a certain range, then the $\mathrm{R} \wedge 2$ will tend to a stable range. This study has not carried out the research.

\section{Acknowledgements}

The research work was supported by Fundamental Research Support Project "Research on Carbon Sinks near the Coast in Tianjin Port (TKS140214)" and Fundamental Research Support Project "The Research of VOCs Emissions of Crude Oil Inventory and Reuse Technology in Loading and Unloading Process in Water Transport Engineering (TKS140218)”.

\section{Reference}

[1] Monitoring the atmosphere aerosol optical characteristics using hyper spectralremote sensing in Hangzhou region [J]. Acta Sciential Circumstance, 2008, 28(9): 1894-1903.

[2] Wang Jing, Yang Fumo, Wang Dingyi, et al.. Characteristics and relationship of aerosol optical thickness and PM2.5concentrationover Beijing [J]. Journal of the Graduate School of the Chinese Academy of Sciences, 2010, 27(1): 10-16.Luigi T.De Luca, Propulsion physics (EDP Sciences, Les Ulis, 2009).

[3] Tang Jiakui, Xue Yong, Yu Tong, et al.. Remote sensing retrieval of aerosol of MODIS [J]. Science China Earth Sciences, 2005, 35(1): 471-481.

[4] Ma JinJi, Qiao Yanli, Yang Shizhi, et al.. Using MODIS image to retrieve aerosol optical characteristic over coast of China [J]. ActaOptica Sinica, 2009, 25(8): 2039-2045.

[5] Li Dong, Chen Wenzhong. Comparison of remote sensing aerosol optical depth from MODIS data with in-situ sky radiometerobservations over east China sea [J]. Acta Optica Sinica, 2010, 30(10): 2827-2836.

[6] Yang Honglong, Lu Chao, Liu Aiming, et al. Analysis of aerosol optical properties and sources at Shenzhen[J]. Acta Optica Sinica, 2013, 33(12): 1201003.

[7] Liu Guiqing, Mao Jietai, Li Chengcai. Optical depth study on atmospheric aerosol in Yangtze River Delta region [J]. EnvironmentalProtection, 2003, (8): 5054.

[8] Wang Xinqiang, Yang Shizhi, Zhu Yonghao. Aerosol optical thickness retrieval over land from MODIS data based on the inversionof 6S model [J]. Chinese J Quantum Electronics, 2003, 20(5): 629634.

[9] Peng Nina, Yi Weining, Fang Yonghua. Retrieval of aerosol optical depth based on 400 1000 nm dense 
dark vegetation algorithm[J]. Infrared and Laser Engineering, 2008, 37(5): 878-883.

[10] Y J Kaufman, Andrew E Wald, Lorraine A Remer, et al.. The MODIS $2.1 \mu \mathrm{m}$ channel-correlation with visible reflectance for use inremote sensing of aerosol [J]. IEEE Trans Geoscience and Remote Sensing, 1997, 35(5): 1286-1298.

[11]C Robert Levy, A Remer Lorraine. A new algorithm for retrieving aerosol properties over land from MODIS spectral reflectance [J]. JGeophys Res, 2006. [12]Fan Jiao, Guo Baofeng, He Hongchang. Retrieval of Aerosol Optical Thickness with MODIS Data over Hangzhou[J]. Acta Optica Sinica, 2015, 35(1) : 0101001-1- 0101001-9. 